A Concise History of Chemistry. By T. P. Hilditch. Pp. 263, 12mo. New York, D. Van Nostrand Co. 1911.

This little treatise is an attempt to lay before students of chemistry a condensed summary of chemical history. In many respects it is likely to be a useful book, although its conciseness is often an obstacle to intelligibility. Its use demands a rather wider range of knowledge than the arerage student is likely to possess. The chapter upon the earlier history of chemistry, and the evolution of the science, covers familiar ground, but with much omission of detail; the chapters dealing with more specific subjects are very unequal in value. The author is an organic chemist, and therefore the chapter upon organic chemistry is remarkably full and well handled. It includes a number of tabular statements illustrating classes of compounds, which will doubtless be found valuable for reference. The chapter on inorganic chemistry is much less satisfactory, and hardly up to date. Apart from a brief reference to the use of the rare earths in incandescent lighting, there is little or nothing relative to the modern utilization of the less common metals, and the paragraph dealing with synthetic mineralogy is even misleading. Physical chemistry receives rather better treatment, but even here the phase rule is given inadequate space and in the index it is credited to Wolcott Gibbs. This error, which may be due to the indexer rather than to the author, is one of several indications that Mr. Hilditch is unfamiliar with American work. For example, Classen is credited with the introduction of electrolytic methods of chemical analysis, an advance which was really initiated by Wolcott Gibbs, and to which Edgar F. Smith has been a chief contributor. So also, although Richards is barely mentioned on page 202, his name is omitted from the tabular statement of atomic weight methods which follows. In spite of these defects the volume may be serviceable to advanced students.

\section{F. W. Clarke}

An Introduction to the Chemistry of Paints. By J. Newton Friend, Ph.D., D.Sc. New York, Longmans, Green \& Co. Pp. 204, 8 vo.

This book is designed to present this subject to those who have had no training in physics or chemistry, and may be regarded as an unqualified success. It makes no claim to be encyclopædic, and yet one finds terms and descriptions not given in much larger works.

One or two errors have crept in, such for example as the saponification numbers (p. 126) being given as 19.3 , etc., when they are ten times as large: another is the position of the thermometer bulb in Fig. 16 which is much too low.

It is an excellent book and may be cordially recommended to all desiring information in this branch of technology.

A. H. GILL

\section{THE WORK OF THE MARINE BIOLOGICAL STATION OF THE O. S. BUREAU OF FISHERIES, AT BEAUFORT, N. C., DURING THE YEAR 1910}

A NuMBer of the investigations of the preceding year were continued and several new lines of work were begun. The equipment of the laboratory was maintained and a number of additions were made to the same. A launch, operated by two gasoline engines, was substituted for the steam-launch formerly used. The new launch is of small draft, which feature enables it to be used for dredging and for other operations in the vicinity of Beaufort. In addition to this vessel, the station has been equipped with a motor-boat, a sailboat and twelve rowboats.

During July and August the laboratory was supplied as usual with electric lights. During the same period a mess was conducted at the station for the use of the scientific staff. The cost of table board for each member was five dollars per week, the same as during the preceding year. The laboratory was supplied with running fresh and salt water throughout the year. The small storage ca- 